\title{
Psychometric Evaluation of the Healing After Gender-Based Violence Scale: An Instrument for Cross-Sectional and Longitudinal Assessment of Recovery Progress for Women-Identifying Survivors
}

\author{
Laura Sinko $^{1}$ (1) $\cdot$ Zeynep Zonp Özaslan ${ }^{2} \cdot$ Chris Schaitkin $^{3} \cdot$ Denise Saint Arnault $^{3}$ \\ Accepted: 30 September 2021 / Published online: 21 October 2021 \\ (c) The Author(s), under exclusive licence to Springer Science+Business Media, LLC, part of Springer Nature 2021
}

\begin{abstract}
Purpose The Healing after Gender-based Violence Scale (GBV-Heal) was developed to measure the holistic recovery processes of woman-identifying survivors of gender-based violence (GBV). The GBV-Heal asks survivors to evaluate a series of statements based on perceptions of one's lowest point and how they currently feel. These scale response options create lowest point, current feelings, and difference scores to evaluate the healing outcome cross-sectionally. This manuscript aims to evaluate the psychometric properties of the GBV-Heal to understand its usefulness for research and practice.

Method Instrument evaluation consisted of two phases analyzing online survey data from two GBV survivor samples recruited from online health research portals in the United States. In Phase One $(N=236)$, we conducted factor analyses and evaluated convergent/discriminant validity using depression, anxiety, posttraumatic stress, posttraumatic growth, and wellbeing measures. In Phase Two $(N=47)$, we evaluated GBV-Heal response consistency via test-retest within two weeks. Results Results showed that the scale's final model included 4 components with 18 items, explaining $61.2 \%$ and $65 \%$ of the overall scale variances for "at my lowest point" and "my current feelings," respectively. The GBV-Heal difference score showed a weak positive correlation with wellbeing and posttraumatic growth scores and a weak negative correlation with depression, anxiety, and PTSD scores. Test-retest revealed Pearson $r$ correlations of 0.82, 0.82, and 0.69 for the lowest point, current feelings, and difference scores respectively.

Conclusion These findings substantiate the reliability and validity of our instrument as an outcome measure that can be used both cross-sectionally and longitudinally with survivors of GBV.
\end{abstract}

Keywords Instrument $\cdot$ Healing $\cdot$ Gender-based violence $\cdot$ Sexual assault $\cdot$ Intimate partner violence $\cdot$ Recovery

Laura Sinko

laura.sinko@temple.edu

Zeynep Zonp Özaslan

zeynepo@umich.edu

Chris Schaitkin

cschaitkin@gmail.com

Denise Saint Arnault

starnaul@umich.edu

1 Department of Nursing, Temple University College of Public Health, 3307 North Broad Street, Philadelphia, PA 19140, USA

2 University of Michigan School of Nursing, Postdoctoral Fellow of TUBITAK, Turkey, Ann Arbor, MI, USA

3 Department of Health Behavior and Biological Sciences, University of Michigan School of Nursing, Ann Arbor, MI, USA

\section{Background}

Gender-based violence (GBV) is violence perpetrated against another rooted in the power dynamics of gender or violence that disproportionately impacts individuals of a particular gender (European Commission, 2021). Womenidentifying individuals are disproportionately impacted by GBV, which can include "any act of verbal or physical force, coercion or life-threatening deprivation, directed at an individual woman or girl that causes physical or psychological harm, humiliation or arbitrary deprivation of liberty and that perpetuates subordination" (Heise et al., 2002, pg S6). Such acts may include physical, sexual, verbal, emotional, economic, and psychological abuse in childhood or adulthood and threats or coercion based on biological sex or gender identity. It is estimated that one in three women worldwide 
experiences GBV events in their lifetime (World Health Organization, 2013).

GBV, mainly due to its root in the dynamics of power and social order in society, is uniquely detrimental to survivor wellbeing (Rodelli et al., 2021). For example, previous research has revealed that because GBV is often normalized in society, survivors may struggle to recognize, escape from, seek help for, or heal from violence (Fugate et al., 2005; Morrison et al., 2006; Sinko et al., 2021b). As a result, many survivors have lasting physical and mental health symptoms and difficulties reintegrating into the environments that have harmed them (Sinko et al., 2020b). The healing experience after GBV is a multidimensional, iterative, non-linear journey requiring courage, patience, and active engagement in one's recovery (Sinko et al., 2021a). This paper aims to describe the dimensions of healing and examine the psychometric evaluation of a holistic instrument to measure healing after GBV.

\section{Impact of GBV}

Because violence against women and girls has been so widespread, these instances can be normalized or minimized, impacting how individuals process and heal from these experiences (Aghtaie et al., 2018). When a person is exposed to GBV, how they experience it dramatically influences whether they believe it is traumatic. According to the Substance Abuse and Mental Health Services Administration, trauma consists of three "E's": the event( $s$, how individuals experience these events, and ultimately the effect of the event(s) on the individual's functioning and mental, physical, social, and emotional wellbeing (Substance Abuse \& Mental Health Services Administration, 2014). In this way, the individual's perceptions of their GBV event can change over time, as survivors seek healing to process their experiences, find meaning, and reconnect with themselves and the world around them (Sinko et al., 2021a).

GBV can disrupt core beliefs about the world, others, and the self, associated with adjustment problems and decreased relational wellbeing (Sinko et al., 2020a; Kaufman et al., 2018). The emotional suffering caused by GBV (feelings of shame, self-blame, fear, and self-doubt) can also cause individuals to isolate themselves from society (Sinko et al., 2021a). This social withdrawal is especially true in cases where the survivor knows the perpetrator, and the intentional harm inflicted by them causes feelings of betrayal of interpersonal trust (Martin et al., 2013). Previous research indicates that traumatic events characterized by high betrayals, such as those seen in most types of GBV, are more strongly related to subsequent distress and therefore may require differential pathways to healing when compared with low betrayal trauma (e.g., loss of a loved one by accidental death or a natural disaster) (Freyd et al., 2005; Gómez et al., 2016; Martin et al., 2013).
Research has documented the lasting mental health symptoms and difficulties survivors face when reintegrating into the environments that have harmed them as a result (Sinko et al., 2021a). The direct threat to personal physical integrity, and the fact that GBV is intentional, intimate harm caused by another, might add additional symptom burden compared with other types of trauma (Shakespeare-Finch \& Armstrong, 2010). For example, Shakespeare-Finch and Armstrong (2010) found that sexual assault survivors had significantly higher PTSD levels and more significant posttraumatic growth (PTG) difficulties relating to others and appreciating life compared to survivors of motor vehicle accidents and those in bereavement. This finding points to differential impacts by trauma type, revealing the potential for unique pathways for healing depending on the type and nature of trauma survivor's experiences.

\section{Healing After GBV}

A qualitative metasynthesis on survivor perspectives of healing after GBV guided this study, defining healing is a multidimensional, iterative, non-linear journey requiring courage, patience, and active recovery engagement (Sinko et al., 2021b). Other terms used in the literature to describe concepts similar to GBV healing include "thriving" (Heywood et al., 2019; Taylor, 2004), "remaking the self" (Oke, 2008), "transformation of identity" (Glumbikova \& Gojova, 2019), and "overcoming" (Flasch, 2017), among others.

The experience of healing after GBV-related events has been synthesized in various ways in the scientific literature to date. For example, a 2009 qualitative metasynthesis described healing after sexual violence, highlighted key domains including the importance of feeling safe, relating to others, and reevaluating the self as elements of the sexual violence healing process (Draucker et al., 2009). In addition, a 2020 review of recovery after intimate partner violence described developmental aspects of recovery, including disentangling from the past, coping with the present, and moving toward the future (Flasch, 2020). Building from these ideas and attempting to merge these concepts, a 2021 qualitative metasynthesis of GBV survivor healing perspectives suggested five core healing themes (AUTHORS, 2021). The first theme was processing one's trauma and reexamining one's experience, allowing the survivor to make meaning and recognize broader contextual factors that reinforce their negative thought patterns (Crann \& Barata, 2016) while also evaluating themselves and their needs. The second theme was managing negative states, allowing survivors to work toward a life not dominated by negative internal dialogue, emotions, and trauma symptoms (Ranjbar \& Speer, 2013). The third theme was rebuilding the self. This healing challenge is especially difficult when survivor's experienced repeated harm from romantic partners or family members. 
Rebuilding the self involves regaining a sense of one's "true self," separate from violence and abuse (Sinko et al., 2020b). Rebuilding the self involves accepting the things they could not change while embracing curiosity to learn more about themselves and their desires. The fourth theme was connecting with others for tangible social support and feelings of belonging, acceptance, and authenticity (Matheson et al., 2015). The final theme was developing a future-oriented perspective that includes regaining hope and feelings of power in one's life. By looking toward the future and finding meaningful fulfillment in their lives, survivors strove to build a future that worked for them separate from their abuse experiences (Ahmad et al., 2013).

\section{Measuring Healing after Gender-based Violence}

Despite the qualitative literature documenting the multidimensional nature of healing after GBV, there is a lack of survivor-centered outcome measures that precisely captures the healing process related to GBV survivorship. Most research has used symptom reduction as a measure of GBV healing. While symptom reduction is an essential aspect of the overall healing experience, this does not attend to the contextual, societal, and cultural influences that might impact healing outside of physical and mental health symptoms (Gómez et al., 2016, Sinko et al., 2021b). For example, common symptoms or diagnoses that have been evaluated in GBV survivors to date in the scientific literature include major depressive disorder, anxiety disorder, dissociative identity disorder, and posttraumatic stress disorder (PTSD). However, the use of diagnoses and symptom clusters, while perhaps helpful for classification and treatment planning, may not fully capture the complexity of these recovery processes. Thus, expanding our recovery evaluation beyond the alleviation of adverse symptoms is critical to understand better the influences of recovery in this population. Moreover, these measures do not attend to the selfhood, social and future-oriented aspects of healing.

Other similar concepts have been advanced to measure trauma recovery, including resilience and PTG. Resilience has been defined as "the ability of individuals facing adversity to utilize resources within psychological, social, and cultural domains that sustain their wellbeing and promote adaptive outcomes" (Schaefer et al., 2018; Ungar, 2012). Here, the authors highlight resource utilization that enables healing or recovery rather than the nature of healing itself.

Some studies have sought to capture healing using growth-focused outcome measures, including the Posttraumatic Growth Inventory (Tedeschi \& Calhoun, 1996); the Social Adjustment Scale-Self-report (Weissman \& Bothwell, 1976); the Brief Resilience Scale (Smith et al., 2008); and the Stress-Related Growth Scale (Park, Cohen, \& Murch, 1996). These measures were created to be generalized to many different forms of trauma cross-sectionally, without reference to the lowest point individuals have experienced before experiencing growth. Because healing is conceptualized as a process, this may limit these instruments' ability to capture perceived changes from baseline without repeated measures. These measures also cannot capture variations in trauma impact, which may have a bearing on healing progress.

While PTG is conceptualized as a multidimensional process similar to healing, PTG is about understanding the impact of trauma on these dimensions rather than the feeling of recovery per se. The PTG Inventory contains some domains relevant to the GBV survivor experience, including the meaning-making processes after trauma, and the associated positive changes in self perceptions, interpersonal relationships, and life philosophies resulting from a traumatic event (Tedeschi \& Calhoun, 1996). However, the concept of PTG is not specific to GBV and may miss important GBV healing nuances. For example, in one study of the 604 individuals in the original sample used to evaluate the inventory, only 5\% had any "criminal victimization" experience (which GBV would fall under in this case), with much of the sample experiencing bereavement (36\%), injury-producing accidents (16\%), or a parental divorce/ a personal relationship break up (15\%; Tedeschi \& Calhoun, 1996). In addition, the way the inventory is structured (e.g., asking the respondent to indicate on a scale of 0-5 if they experienced changes "as a result of their crisis") is a concept that qualitatively may not resonate with the GBV survivor experience, as most attribute their healing to their efforts, not the traumatic event itself (AUTHORS, 2020). This distinction may explain why some outcome measures such as the PTG Inventory have had conflicting results in GBV populations. For example, a study conducted by Kleim \& Ehlers (2009) found that high levels of posttraumatic stress and depression symptoms were correlated to heightened PTG scores in assault survivors. In opposition to these findings, Grubaugh \& Resick (2007) concluded in their study on sexual assault survivors that PTG was not related to psychological distress. Taken together, this shows the complicated relationship with PTG in survivors of GBV and the need for a more focused, healing outcome measure in this population.

\section{The Creation of the Healing After GBV Scale}

The purpose of this study is to evaluate the psychometric properties of the Healing after GBV scale (GBV-Heal), a 31-item instrument aimed to holistically measure the recovery process for women-identifying survivors of GBV (Sinko, Schaitkin, \& Saint Arnault, 2021). The original form of this instrument was created using healing themes and goals derived from the narratives 
of 56 woman-identifying GBV survivors interviewed by the first and senior author. GBV experiences in this sample were not mutually exclusive. They included selfdefined experiences including sexual assault, sexual harassment, intimate partner violence, childhood abuse, or a combination of multiple forms of GBV. Survivors were asked to describe themselves, their recovery journey, and their definitions of healing using the Clinical Ethnographic Narrative Interview- Trauma (Saint Arnault, 2017). This theory-based method is a survivorcentered, trauma-informed interview that examines gender, selfhood, distress, and healing and includes a series of activities including a social network, body map, lifeline, and empirically derived card sort focused on current feelings and symptoms to understand healing goals and desires. Through this data collection method, we were able to understand the survivor's healing journey holistically while creating space for them to bring forward relevant healing concepts.

Core themes identified through these narratives included reconstructing identity, reconnecting with the self, regaining power and control, cultivating worthiness, relating to others, rebuilding hope and a positive worldview, and finding peace (Sinko, Schaitkin, $\&$ Saint Arnault, 2021). Focus groups [two groups-one with service providers $(n=8)$ and one with research experts $(n=6)]$ were then conducted to determine the conceptual clarity of this measure, and relevant revisions were added. These concepts and related quotations were used to develop an iterated version of the GBV-Heal instrument (see Sinko, Schaitkin, \& Saint Arnault, 2021 for further details on instrument development). Cognitive interviews (an interviewing strategy that asks participants to complete the measure while speaking their thoughts aloud) were then used with $12 \mathrm{GBV}$ survivors to pretest instruments and determine the clarity of concepts and items (Drennan, 2003), building additional content validity.This feedback was incorporated into the final instrument used for psychometric testing.

\section{The Current Study}

This study seeks to validate the use of the GBV-Heal through psychometrically evaluating the dimensions of this scale to reduce items, understand its relationships with other instruments in the literature to date, and evaluate its key domains, internal consistency, and test-retest reliability. We also aim to explore the utility of using this scale cross-sectionally and for longitudinal or intervention evaluation. Understanding the psychometric properties of this scale will give us a better understanding of its usefulness both in the clinical and research world.

\section{Methods}

\section{Phase One: Factor Analysis and Construct Validity}

Design and Sample We used a cross-sectional survey design for Phase One of the evaluation of the GBV-Heal. The purpose of this data collection was to identify dimensions of our scale, evaluate convergent and discriminant validity with other instruments in the field, as well as reduce items to minimize participant burden. Phase One was carried out with a convenience sample of individuals over 18 years old who identified as a woman and identified as experiencing GBV (e.g., intimate partner violence, sexual assault, child abuse, stalking). Sampling was carried out using a university health system research portal in Southeastern Michigan, a mechanism designed to connect individuals who had received care through an academic medical center to potential research opportunities. Participants completed an anonymous tenminute online survey, and participation was deemed consent to participate. The survey included the GBV-Heal, demographic, mental health, and growth instruments (detailed below). Because perceptions of what constitutes GBV can vary from person to person, we chose to let participants self-identify as GBV survivors based on the definitions and examples provided in the introduction, as opposed to screening for it. Participants who participated in our study, and provided their mailing address upon completion, were entered into a lottery to win one of six $\$ 25$ Visa gift cards.

Instruments and Measures For Phase One, we collected demographic and GBV history data along with the instruments listed below. Participants were able to self-identify what types of GBV they encountered based on their definitions and understanding of their experience. Participants were given a drop-down list of some common abuse forms (e.g., physical, sexual, emotional/psychological, economic/ financial harm), along with common GBV types (e.g., sexual assault, rape, child abuse, sexual harassment, stalking, intimate partner violence, domestic violence, forced sex work). They also had the possibility of listing "other" and describing their experience if applicable.

The PTSD Checklist for DSM V (PCL-5) was used to assess posttraumatic stress disorder symptoms (Blevins et al., 2015). 2013). Response options are on a five-point Likert scale (anchors: $0=$ 'Not at all' to $4=$ 'Extremely'). A total symptom severity score was obtained by summing responses to the 20 items. A score of 33 is the current clinical cut-off for this scale (Bovin et al., 2016). The PCL-5 has excellent psychometric properties (e.g., test-retest reliability, internal consistency, convergent and discriminant validity; Blevins et al., 2015). In this study, Cronbach's alpha value was calculated as 0.94 for PCL-5. 
The Patient Health Questionnaire-8 (PHQ-8) assessed depression symptoms (Kroenke et al., 2009). The PHQ-8 is an eight-item, self-administered scale based on DSM-IV diagnostic criteria, identical to the PHQ-9 without the suicide item. Each item is scored on a four-point scale with responses ranging from not at all to nearly every day. A PHQ-8 score of 10 or more has been found to have $88 \%$ sensitivity and $88 \%$ specificity for diagnosing major depression based on clinical interviews (Kroenke et al., 2009). In this study, Cronbach's alpha value was calculated as 0.88 for PHQ-8.

The Generalized Anxiety Disorder-7 (GAD-7) was used to measure anxiety symptoms (Spitzer et al., 2006). The response options of the GAD- 7 items are identical to the PHQ-8 and range from 0 to 21 , with scores of $\geq 5, \geq 10$, and $\geq 15$ represent mild, moderate, and severe anxiety symptom levels, respectively (Spitzer et al., 2006). Good internal consistency and test-retest reliability and convergent, construct, criterion, procedural and factorial validity were found to diagnose Generalized Anxiety Disorder (Kroenke et al., 2007; Spitzer et al., 2006). The GAD-7 also has good sensitivity and specificity for the three other anxiety disorders-- panic disorder, social anxiety disorder, and posttraumatic stress disorder (Kroenke et al., 2007). In this study, Cronbach's alpha value was calculated as 0.91 for GAD-7.

The Posttraumatic Growth Inventory (PTGI) was used to measure PTG. This inventory is a 21 -item self-report instrument used for assessing psychological growth following a traumatic event (Tedeschi \& Calhoun, 1996). The PTGI factors include New Possibilities, Relating to Others, Personal Strength, Spiritual Change, and Appreciation for Life. Participants of this study were asked to indicate the degree to which this change occurred in their life for each statement since their most distressing or traumatic GBV experience. Items on the PTGI range from 1 ("I did not experience this change as a result of my crisis") to 6 ("I experienced this change to a very great degree as a result of my crisis"). Scores on the PTGI range from 1 to 126, with higher scores reflecting more significant perceived growth. Tedeschi and Calhoun reported a Cronbach's alpha of 0.90 for the global score (Tedeschi \& Calhoun, 1996). In this study, Cronbach's alpha value was calculated as 0.93 for PTGI.

The Mental Health Continuum-Short Form (MHC-SF) was used to evaluate participant wellbeing. This instrument consists of 14 items evaluating how someone feels the past month on a 6 -point scale $(0=$ never, $5=$ every day; Keyes, 2002; Lamers et al., 2011). Total sum scores on the MHC-SF can range from 0 to 70 , with higher scores indicating higher levels of wellbeing. The MHC-SF has shown excellent internal consistency $(>0.80)$ and discriminant validity in adults in the U.S. (Lamers et al., 2011; Westerhof \& Keyes, 2010). The three-factor structure of MHC-SF-emotional, psychological, and social wellbeing-has been confirmed in nationally representative samples of U.S. adults (Gallagher et al., 2009). In this study, Cronbach's alpha value was calculated as 0.94 for MHC-SF.

The Healing After Gender-based Violence Scale (GBVHeal) measured healing after GBV (AUTHORS, 2021). The GBV-Heal consists of 31 statements about one's views of themselves, others, and the world using a five-point Likert scale, with $0=$ "Not at all" to $4=$ "To a great extent." The GBV-Heal asks the respondent to evaluate each statement twice: their perceptions of how they felt at their lowest point after GBV and another referencing their current feelings. The difference of these scores is calculated and added to get a total sum recovery score. The results regarding reliability are presented in the results section.

Analysis The data were analyzed using IBM Statistical Package for the Social Sciences Statistics for Windows version 25 software. Descriptive statistics (i.e., mean, standard deviation [S.D.], frequency, and percentage) were calculated for all items to describe the sample's characteristics.

Exploratory and confirmatory factor analysis The GBVHeal's psychometric properties were analyzed using exploratory and confirmatory factor analysis (EFA, CFA), including orthogonal varimax rotation. Items with a factor loading lower than 0.30 were excluded from further analyses (Tabachnick \& Fidell, 2013). Significance was assessed at a $p<0.05$ level. In addition, the Kaiser-Meyer-Olkin (KMO) proficiency measurement and Bartlett's sphericity test were used to measure suitability for factor analysis. Cronbach's alpha was utilized to examine internal consistency for the scale reliability, and item-total correlations were examined to determine item relevance or redundancy in the overall scale. While validating a scale, we performed both the CFA and EFA in the same data set.

Convergent and Discriminant Validity The average variance extracted (AVE) and the composite reliability (C.R.) values were calculated to test the convergent and discriminant validity of the scale with the wellbeing and distress measures. Convergent validity was examined using the posttraumatic growth inventory (PTGI) and the Mental Health Continuum- Short Form (MHC-SF) wellbeing measures. Correlation coefficients for these instruments were also calculated. Discriminant validity was examined using the posttraumatic stress disorder (PCL-5), depression (PHQ-8), and anxiety (GAD-7) scores.

External Validity External validity is evaluated using the differential healing sum scores. The differential healing sum score is calculated by subtracting the lowest point score (at my lowest point- "Healing 1") from the current point (my 
current feelings - "Healing 2"). The difference between these scores hypothetically represents progress in healing, and this difference was used to examine correlations with wellness and distress total scores.

\section{Phase Two: Reproducibility}

Design and Sample After reducing items, an additional quantitative survey was conducted to determine test-retest reliability in Phase Two. Phase Two was carried out with a new sample of GBV survivors who were also individuals over the age of 18 years old, identified as a woman, and identified as experiencing GBV. Participants were recruited online through the national research portal ResearchMatch $(N=64)$. ResearchMatch is a national health volunteer registry created by several academic institutions and supported by the U.S. National Institutes of Health. It has a large population of volunteers who have consented to be contacted by researchers about health studies for which they may be eligible. Participants who agreed to be a part of our study took a short online survey (around seven minutes in total), with demographic and trauma history variables along with the GBV-Heal, and were followed up two weeks later with the same survey to understand the response consistency of our instrument. Participants who completed this portion of our study were entered into a lottery to win one of five $\$ 20$ Amazon gift cards.

Instruments and Measures For Phase Two, we collected demographic and GBV history data along with GBV-Heal data listed below. Participants were able to self-identify what types of GBV they encountered based on their definitions and understanding of their experience. Participants were given a drop-down list of some common abuse forms (e.g., physical, sexual, emotional/psychological, economic/ financial harm), along with common GBV types (e.g., sexual assault, rape, child abuse, sexual harassment, stalking, intimate partner violence, domestic violence, forced sex work). They also had the possibility of listing "other" and describing their experience if applicable.

The Healing After Gender-based Violence Scale (GBVHeal) measured healing after GBV (AUTHORS, 2021). The GBV-Heal consists of 31 statements about one's views of themselves, others, and the world using a five-point Likert scale, with $0=$ "Not at all" to $4=$ "To a great extent." The GBV-Heal asks the respondent to evaluate each statement twice: their perceptions of how they felt at their lowest point after GBV and another referencing their current feelings. The difference of these scores is calculated and added to get a total sum recovery score. The results regarding reliability are presented in the results section.
Analysis After reducing items, a new dataset was analyzed using descriptive statistics for the study population of those who completed the retest fully and without error $(N=47)$, as calculated using $\mathrm{R}$ version 4.0.2 (R Core Team, 2020). Test-retest reliability was explored through several measures at both the total score and item levels. Paired sample t-tests were performed for the subjects' reported the lowest point (Healing 1), current feelings (Healing 2), and differential healing sum scores. Pearson's r correlations were calculated using R 4.0.2.

Intraclass correlation coefficients (ICCs) are quantifications of the degree to which data within each group (i.e., healing 1, healing 2, and GBV-Heal) were related, were calculated for each according to agreement model 2.1 using Microsoft Excel software (Shrout \& Fleiss, 1979). Absolute reliability, the degree to which repeated measurements vary for an individual, was calculated through standard error of measurement (SEM), an estimate of distribution around an individual's "true" response, which is equal to the standard deviation of the difference between test and retest sum scores divided by $\sqrt{ } 2$; the smallest detectable change (SDC), i.e., the change in an instrument's score that is beyond measurement error, equal to the $\mathrm{SEM} \times 1.96 \mathrm{x}$ $\sqrt{ } 2$; and the limits of agreement (LOA), within which data are considered to agree, calculated as the mean difference between sum scores at test and retest $\pm 1.96 \times$ the standard deviations (Weir, 2005).

Taken together, these measures indicate how much two scores can vary among stable subjects, i.e., the variation within which a subject's score is considered stable across the two periods. At the item level, percentage agreement (P.A.) was calculated for each item to demonstrate the degree of agreement between scores at test and retest. Additionally, floor and ceiling effects were calculated for each item to assess any clustering at the instrument's lowest or highest possible responses, both for Healing 1 (perceptions of one's lowest point) and Healing 2 (one's current feelings).

\section{Results}

\section{Phase One}

\section{Sample Characteristics}

Two hundred thirty-six women completed the survey in full. Participants ranged in age from 18 to $71(M=33.7$, $S D=12.97)$. In our sample, 185 participants were white, 15 were African American or Black, 19 were Asian, 13 were Hispanic or Latinx, and four were Native American. Most of our sample was currently working for payment or profit $(n=119)$, but 66 participants listed themselves as a student, 
16 unable to work due to permanent sickness or illness, 17 as unemployed, eight as retired, and 10 as their predominant role is looking after the home or other family members. For the highest level of education, 25 participants had graduated high school, 66 were current college students, 14 graduated with a technical degree, 58 had their undergraduate degree, 52 had a graduate degree, 19 had some post-graduate experience, and two listed themselves as "other." Sample characteristics for both Phase One and Phase Two can be found in Table 1.

\section{Exploratory Factor Analysis}

Exploratory factor analysis (EFA) was used to carry out the construct analysis of the GBV-Heal. First, we looked

Table 1 Demographic and GBV-related characteristics of participants in Phase One and Phase Two

\begin{tabular}{|c|c|c|}
\hline \multicolumn{3}{|c|}{ Phase One Sample Characteristics of Women $(N=236)$} \\
\hline Age, $y$ mean $(\mathrm{SD})$ & 33.7 & 13 \\
\hline \multicolumn{3}{|l|}{ GBV Experiences, n (\%) } \\
\hline Domestic violence & 104 & $44.1 \%$ \\
\hline Sexual Assault & 126 & $53.4 \%$ \\
\hline Rape & 85 & $36.0 \%$ \\
\hline Child abuse & 74 & $31.4 \%$ \\
\hline Sexual harassment & 110 & $46.6 \%$ \\
\hline Stalking & 74 & $31.4 \%$ \\
\hline Other relationship violence & 63 & $26.7 \%$ \\
\hline Forced prostitution & 6 & $2.5 \%$ \\
\hline \multicolumn{3}{|l|}{ Violence Types } \\
\hline Psychological/emotional & 196 & $83.1 \%$ \\
\hline Sexual & 165 & $69.9 \%$ \\
\hline Physical & 132 & $55.9 \%$ \\
\hline Economic/financial & 59 & $25.0 \%$ \\
\hline \multicolumn{3}{|c|}{ Phase Two Sample Characteristics of Women $(N=47)$} \\
\hline Age, $y$ mean $(\mathrm{SD})$ & 36.7 & 12.6 \\
\hline \multicolumn{3}{|l|}{ GBV Experiences, n (\%) } \\
\hline Domestic violence & 18 & $38.3 \%$ \\
\hline Sexual Assault & 34 & $72.3 \%$ \\
\hline Rape & 21 & $44.7 \%$ \\
\hline Child abuse & 16 & $34.0 \%$ \\
\hline Sexual harassment & 28 & $59.6 \%$ \\
\hline Stalking & 15 & $31.9 \%$ \\
\hline Other relationship violence & 14 & $29.8 \%$ \\
\hline Forced prostitution & 1 & $2.1 \%$ \\
\hline \multicolumn{3}{|l|}{ Violence Types } \\
\hline Psychological/emotional & 43 & $91.5 \%$ \\
\hline Sexual & 39 & $83.0 \%$ \\
\hline Physical & 24 & $51.1 \%$ \\
\hline Economic/financial & 15 & $31.9 \%$ \\
\hline Other^$^{\wedge}$ & 1 & $2.1 \%$ \\
\hline
\end{tabular}

$\wedge$ Forced physical restraint separately at the Healing 1 (perceptions of lowest point) and Healing 2 (current feelings) scores. The KMO value of sampling adequacy for the sample's responses was 0.93 for the Healing 1 scores, indicating EFA's appropriateness (Cerny $\&$ Kaiser, 1977). Bartlett's sphericity test provided a $p$-value of $<0.01(\chi 2(153)=1865.854)$, so the null hypothesis could be rejected, and the factorability of the correlation matrix was supported (Sharma, 1996). EFA using principal component analysis with varimax rotation was conducted, and four components with eigenvalues exceeding 1 were identified (Girden \& Kabacoff, 2010), explaining 61.2\% of the variance observed. In total, 13 items $(1,6,7,8,9,10,11,13$, $14,15,17,22,31)$ loaded weakly $(<0.30)$, and thus were removed from subsequent EFA iterations. The final model for Healing 1 included four components based on eighteen of the original 31 items. This model explained $61.2 \%$ of the overall scale variance observed. The factor analysis matrix is presented below in Table 3. The Cronbach's alpha measure of internal consistency for the 18 -item scale was 0.92 . The Cronbach's alphas for the subscales are shown in Table 2.

The KMO value of sampling adequacy for the sample's responses is 0.94 for the Healing 2 (current feelings) scores, indicating EFA's appropriateness (Cerny \& Kaiser, 1977). Bartlett's sphericity test provided a $p$-value of $<0.01$ $(\chi 2(153)=2309.786)$, so the null hypothesis could be rejected, and the factorability of the correlation matrix was supported (Sharma, 1996). Exploratory factor analysis using PCA with varimax rotation was conducted, and four components with eigenvalues exceeding 1 were identified (Girden \& Kabacoff, 2010), which explained $65 \%$ of the variance observed. Thirteen items loaded weakly $(<0.30)(1,6,7,8,9,10,11,13,14$ $, 15,17,22,31)$, so these items were removed from subsequent EFA iterations. The final Healing 2 model included four components based on eighteen of the original 31 items found in the Healing 1 analysis. This model explained $65.0 \%$ of the overall scale variance observed. The factor analysis matrix is presented below in Table 3. The Cronbach's alpha measure of internal consistency for the 18-item scale was 0.93 . The Cronbach's alpha of the sub-scales and the complete 18-item scale are shown in Table 3. The descriptive results related to Healing 1 (perceptions of one's lowest point) and Healing 2 (one's current feelings) are given in Table 4.

Our EFA revealed four components: trauma processing and self-advocacy, self-connection, relating to others, and regaining hope and power. Trauma processing and selfadvocacy were operationalized by items related to one's internal dialogue and ability to reach out for help when they need it (e.g., I am able to communicate my needs with others, I feel as though I am not to blame for my experiences, I am able to forgive myself for past behaviors that bring me guilt or shame). Self-connection was operationalized by items relating to one's perceptions of self-understanding and acceptance (e.g., I feel like I know 


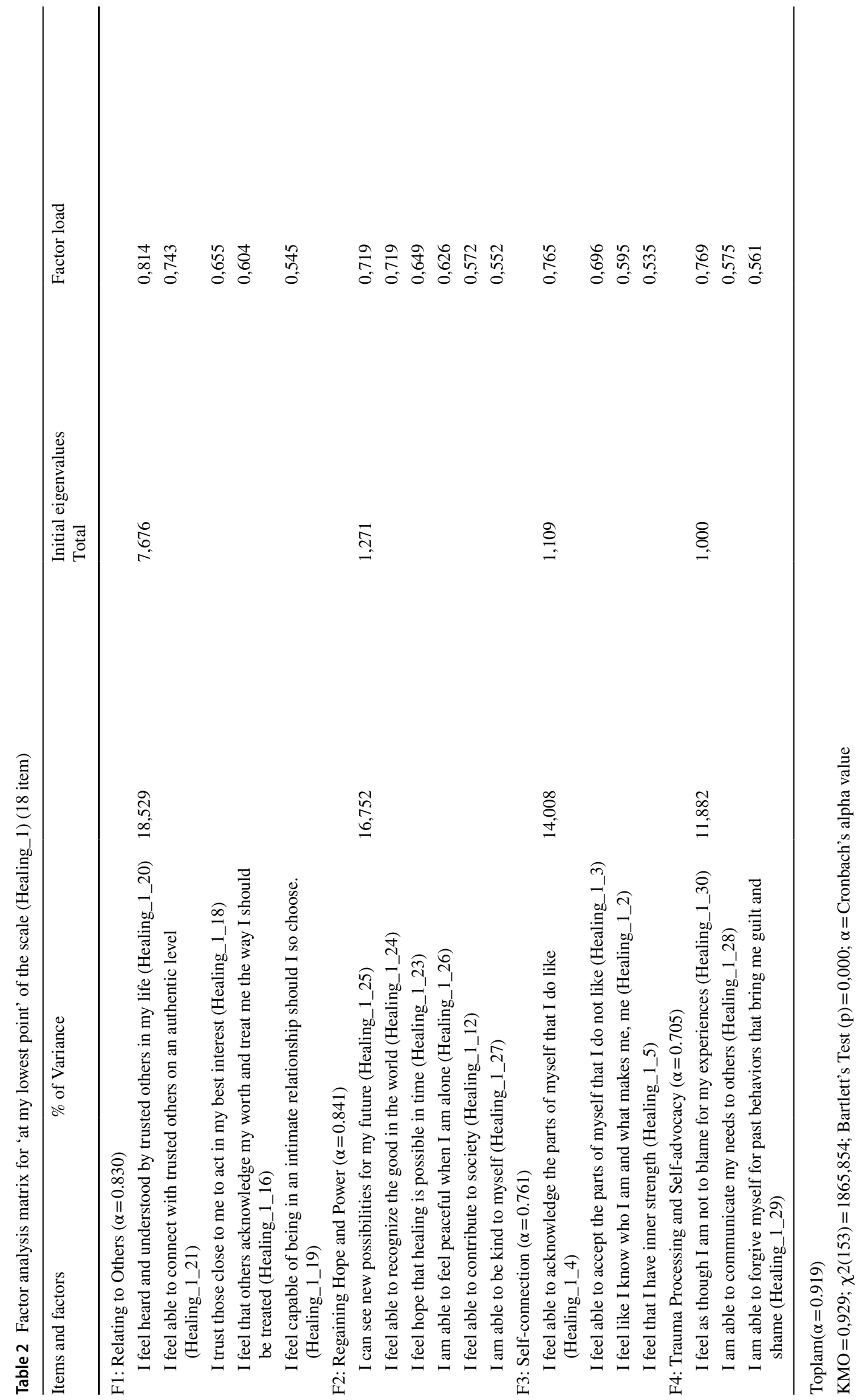


Table 3 Factor analysis matrix for 'my current feelings' of the scale (Healing_2) (18 item)

\begin{tabular}{|c|c|c|c|}
\hline Items and factors & $\%$ of Variance & $\begin{array}{l}\text { Initial } \\
\text { eigen- } \\
\text { values } \\
\text { Total }\end{array}$ & Factor load \\
\hline \multicolumn{4}{|l|}{ F1: Relating to Others $(\alpha=0,861)$} \\
\hline I feel heard and understood by trusted others in my life (Healing_2_20) & 20,341 & 8,634 & 0,784 \\
\hline I feel able to connect with trusted others on an authentic level (Healing_2_21) & & & 0,773 \\
\hline I trust those close to me to act in my best interest (Healing_2_18) & & & 0,749 \\
\hline I feel that others acknowledge my worth and treat me the way I should be treated (Healing_2_16) & & & 0,626 \\
\hline I feel capable of being in an intimate relationship should I so choose. (Healing_2_19) & & & 0,576 \\
\hline \multicolumn{4}{|l|}{ F2: Regaining Hope and Power $(\alpha=0,868)$} \\
\hline I can see new possibilities for my future (Healing_2_25) & 17,965 & 1,244 & 0,766 \\
\hline I feel able to recognize the good in the world (Healing_2_24) & & & 0,673 \\
\hline I feel hope that healing is possible in time (Healing_2_23) & & & 0,620 \\
\hline I am able to feel peaceful when I am alone (Healing_2_26) & & & 0,599 \\
\hline I feel able to contribute to society (Healing_2_12) & & & 0,593 \\
\hline I am able to be kind to myself (Healing_2_27) & & & 0,557 \\
\hline \multicolumn{4}{|l|}{ F3: Self-connection $(\alpha=0,814)$} \\
\hline I feel able to acknowledge the parts of myself that I do like (Healing_2_4) & 15,454 & 1,087 & 0,751 \\
\hline I feel able to accept the parts of myself that I do not like (Healing_2_3) & & & 0,718 \\
\hline I feel like I know who I am and what makes me, me (Healing_2_2) & & & 0,625 \\
\hline I feel that I have inner strength (Healing_2_5) & & & 0,623 \\
\hline \multicolumn{4}{|l|}{ F4: Trauma Processing and Reexamination $(\alpha=0,760)$} \\
\hline I feel as though I am not to blame for my experiences (Healing_2_30) & 12,264 & 1,000 & 0,800 \\
\hline I am able to communicate my needs to others (Healing_2_28) & & & 0,701 \\
\hline I am able to forgive myself for past behaviors that bring me guilt and shame (Healing_2_29) & & & 0,634 \\
\hline
\end{tabular}

Toplam $(\alpha=0,934)$

$\mathrm{KMO}=0,938 ; \chi 2(153)=2309,786 ;$ Bartlett's Test $(\mathrm{p})=0,000 ; \alpha=$ Cronbach's alpha value

Table 4 Descriptive Statistics for Instrument Subscales $(N=236)$

\begin{tabular}{lrrrr}
\hline Factors & M & SD & Min & Max \\
\hline Relating to Others (Healing 1) & 10,32 & 4,29 & 5,00 & 24,00 \\
Regaining Hope and Power (Healing 1) & 13,30 & 5,30 & 6,00 & 28,00 \\
Self-connection (Healing 1) & 8,02 & 3,43 & 4,00 & 19,00 \\
Trauma Processing and Reexamination (Healing 1) & 5,86 & 2,66 & 3,00 & 14,00 \\
Perceptions of Lowest Point (Healing 1) & 37,53 & 13,29 & 18,00 & 77,00 \\
Relating to Others (Healing 2) & 18,24 & 4,67 & 5,00 & 25,00 \\
Regaining Hope and Power (Healing 2) & 22,77 & 5,09 & 6,00 & 30,00 \\
Self-connection (Healing 2) & 14,72 & 3,36 & 5,00 & 20,00 \\
Trauma Processing and Reexamination (Healing 2) & 10,20 & 2,73 & 3,00 & 15,00 \\
Current Feelings (Healing 2) & 65,96 & 13,67 & 26,00 & 90,00 \\
\hline
\end{tabular}

who I am and what makes me me, I feel able to accept the parts of myself I do not like, I feel able to acknowledge the parts of myself that I do like). Relating to others was operationalized by items that illustrated goals involving authentic, trusting interactions with others (e.g., I feel heard and understood by trusted others in my life, I feel able to connect with trusted others on an authentic level).
Regaining hope and power was operationalized by futureoriented items and illustrated beliefs of a positive future (e.g., I feel hope that healing is possible in time, I feel able to recognize the good in the world, I can see new possibilities for my future). See Table 5 for the final measure and the items included in each subscale. 
Table 5 Final GBV-Heal Instrument After Item Reduction

Gender-based violence (GBV) can encompass such acts as intimate partner violence, sexual violence, child abuse, forced prostitution, genital cutting, and stalking. GBV can have great impacts on our physical, social, mental, and emotional health. Below are statements that depict experiences and feelings people have. Please indicate for each statement below the degree to which this characterizes how you felt at your lowest point after your GBV experience as well as what best describes your current feelings now

$\begin{array}{llll}\text { Not at all A little bit } & \text { Somewhat } & \begin{array}{l}\text { To a } \\ \text { considerable } \\ \text { degree }\end{array} & \begin{array}{l}\text { To a } \\ \text { great } \\ \text { extent }\end{array}\end{array}$

1. I feel like I know who I am and what makes me, me

2. I feel able to accept the parts of myself that I do not like

3. I feel able to acknowledge the parts of myself that I do like

4. I feel that I have inner strength

5. I feel able to contribute to society

6. I feel that others acknowledge my worth and treat me the way I should be treated

7. I trust those close to me to act in my best interest

8. I feel capable of being in an intimate relationship should I so choose

9. I feel heard and understood by trusted others in my life

10. I feel able to connect with trusted others on an authentic level

11. I feel hope that healing is possible in time

12. I feel able to recognize the good in the world

13. I can see new possibilities for my future

14. I am able to feel peaceful when I am alone

15. I am able to be kind to myself

16. I am able to communicate my needs to others

17. I am able to forgive myself for past behaviors that bring me guilt and shame

18. I feel as though I am not to blame for my experiences
At my lowest point

My current feelings

At my lowest point

My current feelings

At my lowest point

My current feelings

At my lowest point

My current feelings

At my lowest point

My current feelings

At my lowest point

My current feelings

At my lowest point

My current feelings

At my lowest point

My current feelings

At my lowest point

My current feelings

At my lowest point

My current feelings

At my lowest point

My current feelings

At my lowest point

My current feelings

At my lowest point

My current feelings

At my lowest point

My current feelings

At my lowest point

My current feelings

At my lowest point

My current feelings

At my lowest point

My current feelings

At my lowest point

My current feelings

\section{Subscales:}

Relating to others: $6,7,8,9,10$

Regaining hope and power:11, 12, 13, 14, 15, 5

Self-connection: $1,2,3,4$

Trauma processing and self-advocacy: $16,17,18$ 


\section{Confirmatory Factor Analysis}

Confirmatory factor analysis indicated that a 4-factor solution was the model that best fit the data. The root mean square error of approximation was within the range of reasonable fit at 0.05 for Healing 1 (perceptions of one's lowest point), at 0.06 for Healing 2 (one's current feelings) (Browne \& Cudeck, 1992). The chi-square/ degrees of freedom value was 1.71 and 1.94 , respectively, which showed an acceptable fit (Hooper et al., 2008). The fit indices of the Healing 2 were improved by creating a covariance between e13 and e14, which have high error values based on the modification indices. The other results related to CFA can be seen in Table 6 .

The analysis further revealed a consensus between the scree plot (see Figs. 1 and 2) and model fit measures in favor of the 4 -factor models.

Four-factor models for CFA are also presented in Figs. 3 and 4.

\section{Discriminant and Convergent Validity}

This model's discriminant and convergent validity were examined by the correlation coefficients, the AVE, the C.R., and the square root of AVE (See Table 7).

Evaluating the average variance extracted (AVE) verifies the proportion of variance of the items that are explained by the construct to which they belong. Just as in evaluating factorial loads, when the AVE values are equal to 0.5 or over, the model converges to a positive result. The C.R. is a less biased estimate of reliability than Cronbachs Alpha; the acceptable value of C.R. is 0.7 and above (Souza et al., 2017). The C.R. values were above 0.70, and the AVE values were 0.50 and above for both scales and factors; thus, the results showed good convergent validity (Hair Jr. et al., 2016). The square roots of AVE must be higher than the correlation between the constructs to have discriminant validity (Souza et al., 2017). For this purpose, correlations between factors were calculated first. It was determined that the square roots of the AVE values were greater than these correlation values showing a good discriminant validity (Hair Jr. et al., 2016).

\section{External Validity}

The sum of the difference scores generated from the GBVHeal showed a weak, positive correlation with the total score of the MHC-SF $(p<0.01: \mathrm{r}=0.348$, alpha $=0.936)$, the PTGI $(p<0.01: \mathrm{r}=0.368$, alpha $=0.890)$, and a weak, negative correlation with the PHQ-8 $(p<0.01$ : $\mathrm{r}=-0.326$, alpha $=0.826)$, the GAD-7 $(p<0.01: \mathrm{r}=-0.211$, alpha $=0.906)$, and the PCL-5 $(p<0.01: \mathrm{r}=-, 266$, alpha $=0.944)$.

The correlations between the Healing 2 (one's current feelings) and symptom scales showed that there was a strong, positive correlation with MHC-SF $(p<0.01$ : $\mathrm{r}=0.770)$, a weak positive correlation with PTGI $(p<0.01$ : $\mathrm{r}=0.362)$, a strong, negative correlation with PHQ-9 $(p<0.01: \mathrm{r}=-0.700)$, GAD-7 $(p<0.01: \mathrm{r}=-0.599)$, and PCL-5 $(p<0.01: \mathrm{r}=-0.652)$.

Phase Two.

\section{Sample Characteristics}

Forty-seven participants completed the survey at both test and retest, ranging in age from 19 to $60(M=36.7$, $S D=12.59$ ). Multiple respondents identified with multiple ethnicities and/or held multiple occupations. 40 participants were white, three were African American or Black, three were Asian, three were Hispanic or Latinx, one was Native American, and one reported being of an unknown race or ethnicity. Most of our sample was currently working for payment or profit $(n=24)$, while seven were students, 13 were unable to work due to permanent sickness or illness, five were unemployed, five were looking after the home or other family members. In terms of highest education received, one participant graduated high school, 10 were current college students, four graduated with a technical degree, 17 had their

Table 6 Fit indices for CFA for both scales

\begin{tabular}{|c|c|c|c|c|}
\hline Fit Index & Acceptable Values & Perfect Values & $\begin{array}{l}\text { Actual Values for Perceived Lowest } \\
\text { Point (Healing 1) }\end{array}$ & $\begin{array}{l}\text { Actual Values for } \\
\text { Current Feelings } \\
\text { (Healing 2) }\end{array}$ \\
\hline CMIN/Df & $0 \leq \chi^{2} / \mathrm{df} \leq 3$ & $3 \leq \chi^{2} / \mathrm{df} \leq 5$ & 1,711 & 1,944 \\
\hline GFI & $0,80 \leq \mathrm{CFI}$ & $0,90 \leq \mathrm{CFI}$ & 0,905 & 0,896 \\
\hline AGFI & $0,80 \leq \mathrm{AGFI}$ & $0,90 \leq \mathrm{AGFI}$ & 0,875 & 0,861 \\
\hline CFI & $0,85 \leq \mathrm{CFI}$ & $0,95 \leq \mathrm{CFI}$ & 0,948 & 0,946 \\
\hline RMSEA & $0,0 \leq \mathrm{RMSEA} \leq 0,05$ & $0,06 \leq \mathrm{RMSEA} \leq 1,0$ & 0,055 & 0,063 \\
\hline NFI & $0,80 \leq \mathrm{NFI}$ & $0,95 \leq \mathrm{NFI}$ & 0,885 & 0,895 \\
\hline TLI & $0,80 \leq \mathrm{TLI}$ & $0,90 \leq \mathrm{TLI}$ & 0,949 & 0,935 \\
\hline IFI & $0,85 \leq \mathrm{CFI}$ & $0,95 \leq \mathrm{CFI}$ & 0,939 & 0,946 \\
\hline
\end{tabular}


Fig. 1 Scree plot for the EFA for "lowest point" (top plot) and "current feelings" (bottom plot)
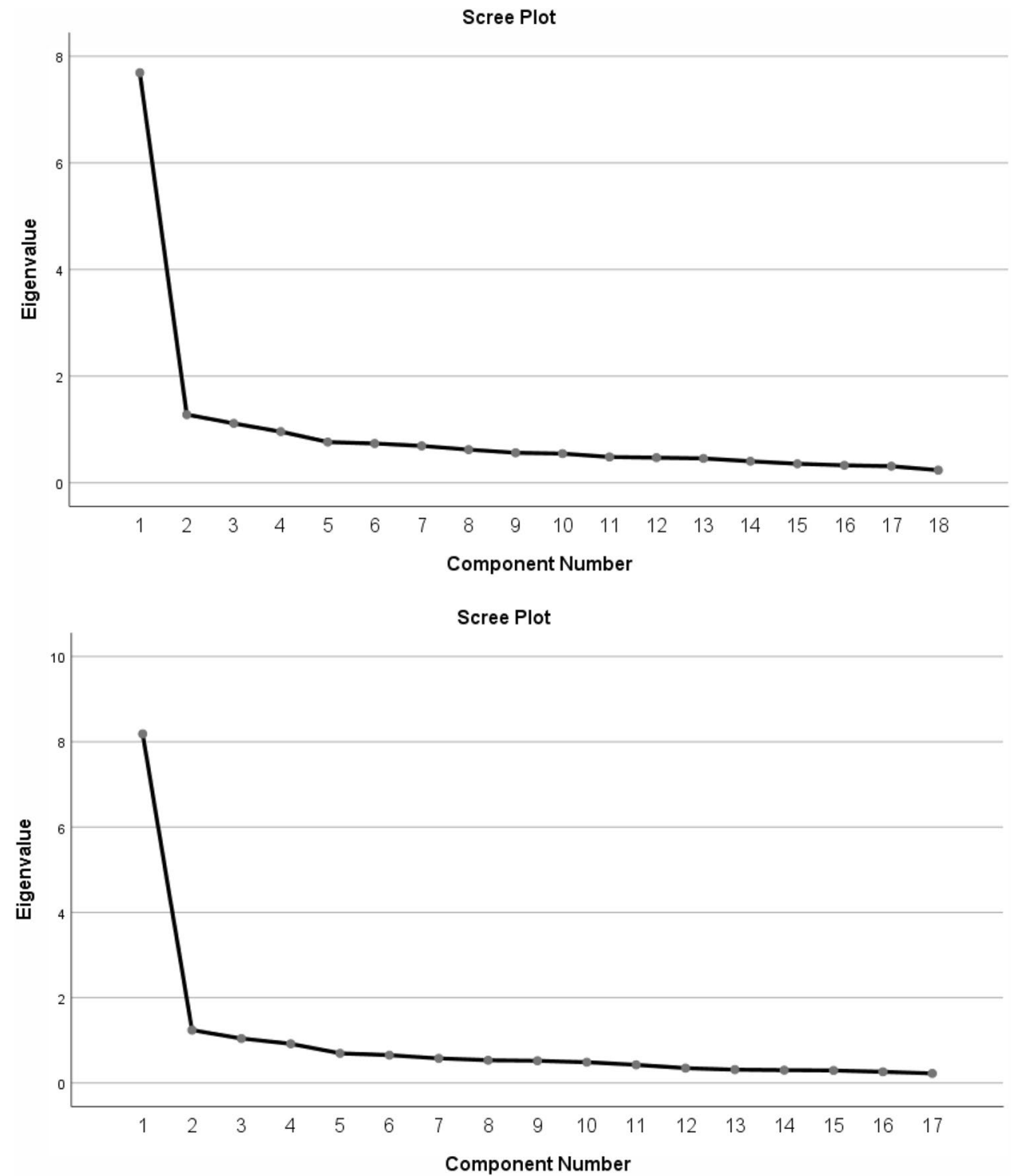

undergraduate degree, 10 had a graduate degree, four had some post-graduate experience, and one did not report their highest level of education. Descriptive statistics relating to the sample's GBV experiences can be found in Table 1.

\section{Test-Retest Reliability}

Compared with the original, Phase One sample, the Phase Two reproducibility sample was slightly older on average, though with similar age ranges (18 to 71 vs. 19 to 60 for phases one and two, respectively). In the reproducibility sample, the number of respondents identifying as African American or Black, Asian, Hispanic or Latinx, or Native American was roughly equivalent to the sample in Phase One; however, multiple respondents selected multiple ethnicities, and the total identifying as white was larger in the reproducibility sample (78.0\% vs. $85.1 \%$ for phase one and phase two, respectively). The Phase Two reproducibility sample had received slightly more education than the Phase One sample, with $36.6 \%$ and $24.6 \%$ of respondents having received undergraduate degrees, respectively. In comparison, the number of those with only a high school diploma was also higher in the phase one sample ( $10.6 \%$ vs. $2.1 \%$, respectively). The percentages of those with graduate degrees and some post-graduate degrees were roughly the same in each group.

Concerning each sample's GBV experiences, many of the experiences tested were similar between the groups; however, the Phase Two reproducibility sample was considerably more likely to have experienced sexual assault than the phase one sample ( $72.3 \%$ vs. $53.4 \%$, respectively), as well as rape (44.7\% vs. $36.0 \%)$ and sexual harassment (59.6\% vs. 46.6\%). The Phase One sample reported a higher domestic violence rate than the phase two sample $(44.1 \%$ vs. $38.3 \%$, respectively). Types of violence experienced also tended to 


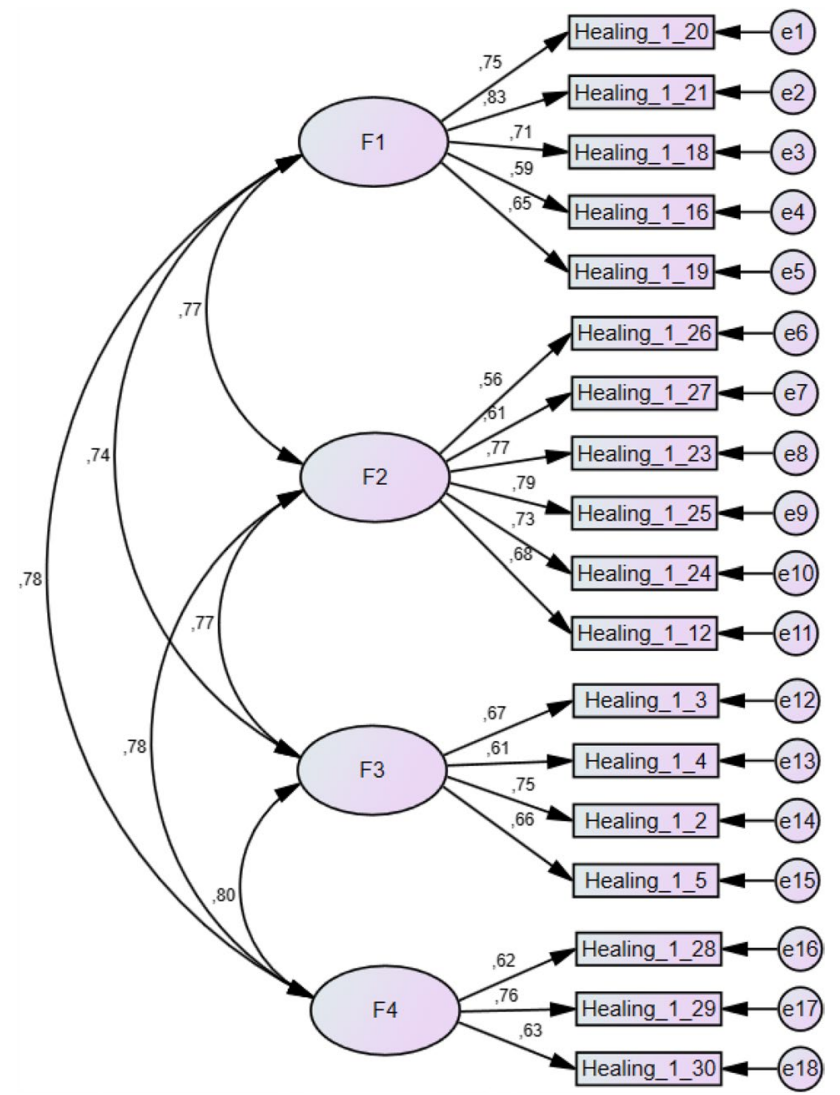

Fig. 2 Results of the CFA of the healing scale for at my lowest point (Healing 1-see Table 3 for items)

be higher in the Phase Two sample, with $91.5 \%$ of respondents reporting psychological/emotional violence, $83.0 \%$ reporting sexual violence, and $31.9 \%$ reporting economic/ financial violence, compared with $83.1 \%, 69.9 \%$, and $25.0 \%$, respectively, in the phase one sample. Physical violence was roughly equivalent for each group (55.9\% and $51.1 \%$ for phase one and two respondents, respectively).

\section{Total Score Reliability and Validity}

Paired sample t-tests were performed to test the hypothesis that the score means were statistically different. We also calculated Pearson $r$ correlations to measure the association between items at test and retest (See Table 8 for results). The Pearson $r$ correlations were $0.82,0.82$, and 0.69 for the lowest point, current feelings, and difference scores.

In terms of absolute reliability, SEM was calculated to be 4.38 points for the healing 1 sum score (perceptions of the lowest point), translating to an SDC of 12.14 points; 5.12 points for the healing 2 sum score (current feelings), and 14.19 SDC; and 7.42 points for overall difference scores, and an SDC of 20.58. The LOA ranged from -12.1 to 10.7 for Healing 1 , from -14.2 to 16.1 for Healing 2, and from -20.6 to 23.9 for

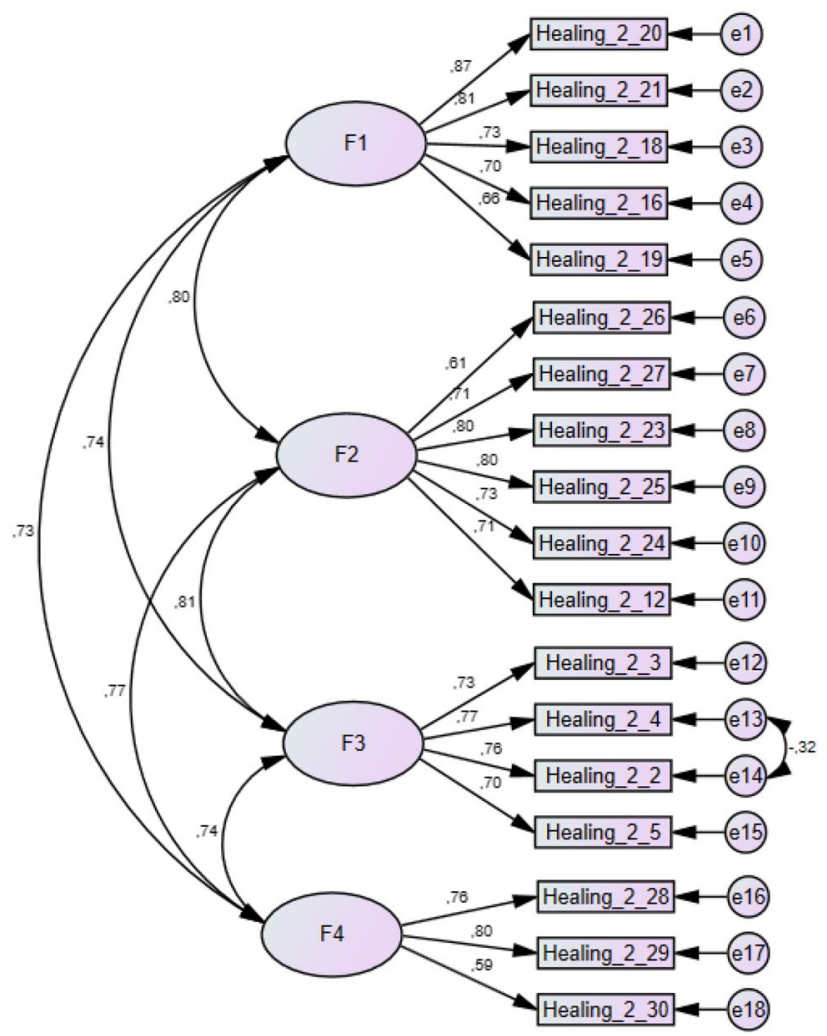

Fig. 3 Results of the CFA of the healing scale for my current feelings (Healing 2-see Table 4 for items)

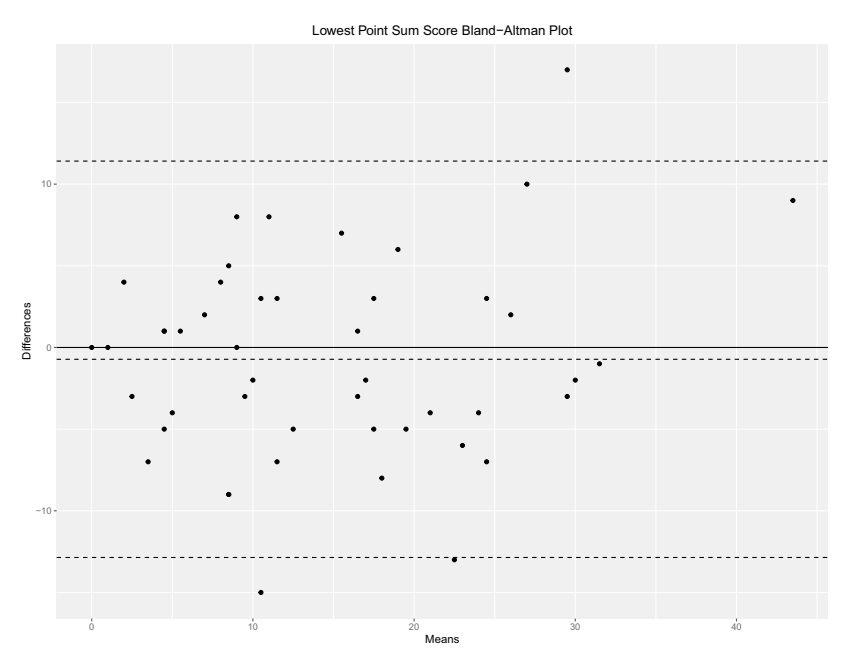

Fig. 4 Bland-Altman Plot of lowest point (Healing 1) sum scores

the overall differential healing sum score. Figure 4 shows a Bland and Altman scatterplot for the lowest point scores plots the difference between scores at the test and the retest against the mean of the sum scores from test and retest. The dotted line represents the retest bias in Fig. 4, which the paired sample 
Table 7 Discriminant and convergent validity for "my lowest point" (Healing 1) and "my current feelings" (Healing 2)

Table 8 Results of t-test and Pearson's $r$ correlations for Time 1 and Time 2 scores across three sum scores

\begin{tabular}{|c|c|c|c|c|c|c|c|c|}
\hline \multirow[b]{2}{*}{ Perceived Lowest Point (Healing 1) } & \multirow[t]{2}{*}{ AVE } & \multirow{2}{*}{$\begin{array}{l}\text { Square } \\
\text { root of } \\
\text { AVE }\end{array}$} & \multicolumn{6}{|l|}{ CR } \\
\hline & & & & & F1_1 & $\mathrm{F} 2 \_1$ & F3_1 & F4_1 \\
\hline Relating to Others & 0,51 & 0,71 & 0,84 & $\mathrm{r}$ & 1.000 & & & \\
\hline Regaining Hope and Power & 0,51 & 0,71 & 0,85 & $\mathrm{r}$ & $0,627^{* *}$ & 1.000 & & \\
\hline Self-connection & 0,5 & 0,71 & 0,77 & $\mathrm{r}$ & $0,569^{* *}$ & $0,658^{* *}$ & 1.000 & \\
\hline Trauma Processing and Reexamination & 0,51 & 0,71 & 0,71 & $\mathrm{r}$ & $0,568^{* *}$ & $0,555^{* *}$ & $0,571^{* *}$ & 1.000 \\
\hline Current Feelings (Healing 2) & & & & & F2_1 & F2_2 & F3_2 & F4_2 \\
\hline Relating to Others & 0,57 & 0,75 & 0,87 & $\mathrm{r}$ & 1.000 & & & \\
\hline Regaining Hope and Power & 0,53 & 0,73 & 0,87 & $\mathrm{r}$ & $0,689^{* *}$ & 1.000 & & \\
\hline Self-connection & 0,55 & 0,74 & 0,83 & $\mathrm{r}$ & $0,613^{* *}$ & $0,685^{* *}$ & 1.000 & \\
\hline Trauma Processing and Reexamination & 0,53 & 0,73 & 0,76 & $r$ & $0,561^{* *}$ &, $602^{* * *}$ &, $592^{* *}$ & 1.000 \\
\hline
\end{tabular}

(AVE): average variance extracted; (CR): composite reliability

\begin{tabular}{llllll}
\hline & Mean (SD) & Mean (SD) & & & \\
\hline & T1 & T2 & t & p & $\mathrm{r}$ \\
Lowest Point $(n=47)$ & $14,36(10.67)$ & $15,09(9.67)$ & $-0,80$ & 0,43 & $0,82^{*}$ \\
Current Feelings $(n=47)$ & $42,68(12.34)$ & $41,74(11.71)$ & 0,89 & 0,38 & $0,82^{*}$ \\
Difference Score $(n=47)$ & $28,32(13.50)$ & $26,66(13.23)$ & 1,08 & 0,28 & $0,69^{*}$ \\
T1 Time 1 / Pre scores, $T 2$ Time 2 / Post scores & & & & \\
\hline
\end{tabular}

${ }^{*}$ significant at $p<0.01$ level t-test has shown not to be statistically significant (Giavarina, 2015).

The dashed lines demonstrate the LOA, outside of which one could say that the difference between scores at test and retest is significant and not due to error. As we can see, 44 of 47 (93.6\%) of subjects fall within the LOA for the Healing 1 sum score. Additionally, 47 (97.9\%) respondents fell within the LOA for Healing 2 and overall differential sum scores.

\section{Floor and Ceiling Effects}

Regarding floor-and-ceiling effects, we observed floor effects ( $>15 \%$ of respondents choosing the lowest possible response) for each item in the scale at Healing 1 (perceptions of the lowest point). The lowest proportion of respondents selecting "Not at all" at their lowest point for any item was nearly one-third of respondents (31.9\%, item 12). Conversely, we observed ceiling effects in nine of the 18 items (items 4, 5, 7, 8, 9, 10, $11,12,13$, and 14), with the highest effect being one-third of respondents $(31.9 \%$, item 4$)$.

\section{Discussion}

The purpose of this study was to evaluate the properties of the newly developed GBV-Heal instrument, a measure that assesses healing progress for survivors of GBV. Development of the dynamic GBV-Heal resulted from the recognition that existing instruments do not attempt to assess healing holistically as described by survivors (AUTHORS, 2020), and the instruments currently used to assess an individual after trauma are typically static, and therefore could not reasonably assess the healing process from baseline to current feelings. Additionally, the concepts measured by other instruments such as PTG and wellbeing do not necessarily equate to the idea of healing. As mentioned before, PTG measures trauma itself as the cause for growth. This conceptualization does not give justice to the immense effort it takes for survivors to engage in healing actions to improve their emotional state. 
Additionally, while wellbeing may be an essential health outcome to measure in conjunction with healing in this population, its constructs do not precisely map onto healing as described by survivors, limiting its ability to adequately capture the impact of interventions that target specific healing domains. Finally, healing from specific traumas, such as GBV, may not follow the same trajectory as other traumatic experiences. Therefore we aimed to measure recovery as survivors have described it in the qualitative literature to date (AUTHORS, 2021).

\section{Phase One Discussion}

Through EFA, we reduced the total number of items in the GBV-Heal from 31 to 18 . This reduction minimized future participant burden and revealed four components: trauma processing and self-advocacy, self-connection, relating to others, and regaining hope and power. These concepts map onto current literature to date describing survivor perspectives of healing after GBV (see Sinko et al., 2021b for review). For example, processing one's trauma and letting go of feelings such as shame, guilt, and self-blame has been cited by survivors as central to their ability to move forward and focus on their recovery without being held back by their negative thoughts (Smith, 2003; Sinko et al., 2021a ). In addition, self-connection and reconstructing one's identity has been voiced as a critical healing component in multiple qualitative studies (Sinko et al., 2019, Sinko et al., 2020a, Sinko 2020b; Crann \& Barata, 2016; Matheson et al., 2015; Oke, 2008) due to how disorienting trauma can be to one's core beliefs about themselves and the world around them. Similarly, relating to others by repairing trust by being able to be authentic and feel accepted by those around them was a goal many survivors in the scientific literature have mentioned striving for (Sinko et al., 2020, Sinko et al., 2020a, Sinko et al., 2020b; Ahmad et al., 2013; Duma et al., 2007; Glumbıkova \& Gojova, 2019; Lewis et al., 2015). Finally, building a feeling of hope that things will get better with time can create cognitive space for new possibilities for survivors, allowing them to continue to focus on their healing despite setbacks (Sinko et al., 2020b, Sinko et al., 2020a, Sinko et al., 2020b; Ahmad et al., 2013; Crann \& Barata, 2016; Glumbikova \& Gojova, 2019; Heywood et al., 2019). Each subscale mentioned demonstrated adequate internal consistency for both Healing 1 (perceptions of one's lowest point) and Healing 2 (one's current feelings), while the overall GBV-Heal difference score demonstrated excellent internal consistency for both Healing 1 and Healing 2. Confirmatory factor analysis supported the four-factor model.

As one might expect, there was a statistically significant positive correlation between GBV-Heal total scores and wellbeing as well as with PTG, indicating that the greater the healing survivors' experience, the greater their wellbeing and PTG. However, the correlations were relatively weak, implying that healing and global growth measures should not be considered interchangeable. We propose that healing is indeed a dynamic process that does not equate perfectly to greater wellbeing. Therefore, the meaning of the difference score can add to the science of understanding trauma healing. Conversely, there were significant negative correlations between healing and depression, anxiety, and posttraumatic stress symptoms. These observed relationships demonstrate the connections between healing and the erosion of trauma symptoms. Yet, as with the measures above, these correlations were weak, suggesting the dimensions of healing captured extend beyond the alleviation of adverse symptomology. Another explanation for the weak correlation scores involves using the sum of the change scores (current feelings-lowest point) as one's total GBV-Heal score. While this was done to demonstrate the utility of using the change score cross-sectionally, stronger correlations were found compared to just "current feelings."

The domains of the GBV-Heal complement existing models. Two GBV-Heal factors, relating to others and selfconnection, are akin to two PTG domains - relating to others and personal strength - which also assesses interpersonal connections and one's feelings toward oneself. However, unlike PTG, the remaining GBV-Heal domains - regaining hope and power and trauma processing and reexamination - demonstrate one's ability to cope and feel empowered despite their trauma, and not as a consequence of it. This distinction is a critical issue that the GBV-Heal seeks to address.

\section{Phase Two Discussion}

Phase Two of our study revealed that participants' healing sum scores for Healing 1 (perceptions of one's lowest point), Healing 2 (ones current feelings), and total difference score was not statistically significant across the two time points (Taylor, 1990). This finding suggests that respondents were not inconsistent in terms of their feelings following their trauma. Additionally, the fact that the difference scores were not statistically different between test and retest suggests that the GBV-Heal can measure healing, despite marginal movement within individual items. While individuals may vary in how they perceive their lowest point after GBV, this measure is the first of its kind to attempt to calculate perceived changes in healing domains cross-sectionally, enabling us to understand the relationships between variables and perceived recovery progress better. Measures of absolute reliability, such as the SDC and LOA, demonstrate that it would take a relatively large deviation at the sum score level to indicate a statistical difference between the responses collected at test and retest. We found that for these measures, only three of $47(6.38 \%)$ respondents fell outside the LOA 
for Healing 1, while only one of 47 (2.13\%) fell outside these limits for Healing 2. Taken together, these findings show that there was not a statistical difference among responses at test and retest for the vast majority of subjects, indicating a high level of reproducibility for the GBV-Heal.

We did observe floor effects in each item within the GBVHeal; in fact, only five of 18 items demonstrated a proportion of respondents lower than $50 \%$. We believe this could be expected of respondents given that they are being asked to recall feelings at their lowest point (Healing 1) following severe trauma. Conversely, we do not see the same for one's current feelings (Healing 2), as although 9 of 18 items demonstrated a ceiling effect, we observe a much smaller effect size: 6 of 9 items fell between 15 and 20\%. Given that the ceiling effects are less frequent and less prominent than the floor effects and that larger sample size could wash away many of the ceiling effects, the reproducibility of the GBV-Heal measure should not be discounted (Simkovic \& Trauble, 2019); Future testing should determine whether these effects are artifacts of the relatively small sample size.

\section{Implications}

Unlike other instruments, the GBV-Heal seeks to measure the healing process after GBV grounded in the voices of survivors who have experienced it. The measure was created after asking 54 survivors about their healing through a holistic interview process, allowing them to discuss themselves socially, how it feels to be in their body, their experiences across time, as well as their current situation and struggles. Currently, limited instruments measure recovery from this lens. This limitation has restricted our clinical ability to assess survivor healing outside of current symptomology and may also limit our discussions about their healing goals and potential barriers. The GBV-Heal can be used as a clinical tool to assess trauma treatment effectiveness and provide a more holistic survivor intake to understand where individuals are in their healing process and what they may want to work on better.

Additionally, in the research context, measures specifically about GBV and recovery are limited. Many existing measures are non-specific regarding the type of traumatic event, even though the effects of such events and pathways to healing may be vastly different (ShakespeareFinch \& Armstrong, 2010) or treated differently by society as a whole. Further, many measures, such as ones that measure PTG, link the growth experienced after trauma as a result of the traumatic event itself. In contrast, the GBV-Heal equates recovery progress as a result of a survivor's healing efforts and actions, making it potentially more empowering and relatable for survivors of GBV (e.g., I feel able to connect with trusted others on an authentic level, I am able to be kind to myself, I am able to communicate my needs with others).
A survivor-centered healing outcome measure such as the GBV-Heal can have significant implications for the research context, capturing variables that may be correlated with healing cross-sectionally and evaluating the effectiveness of new healing interventions.

\section{Limitations}

This study is not without limitations. For example, our predominantly white, college-educated sample may not represent the larger population in the United States. Our need to administer online surveys due to COVID-19 limited our ability to access individuals who may be technologically isolated or have limited technological literacy. In addition, it is generally accepted that specific segments of the population are more susceptible to GBV, such as transgender women of color, in the United States and around the world (Lanham et al., 2019). To that end, while we know our population identified as being women, we did not capture whether these individuals identified as being transgender and did not capture the experiences of a significant number of people identifying as non-binary, agender, or gender fluid. Relatedly, it is understood that different forms of GBV may impact individuals differently, despite having similar gendered underpinnings. Future research, therefore, should explore differences in GBV-Heal scores across different forms of GBV. Finally, this study focused on healing from GBV in a United States context. However, translation and additional testing are underway to understand how these concepts resonate with survivors living outside the United States. Caution should be used, therefore, when trying to use this instrument with more diverse cultural groups without the results of additional testing.

\section{Conclusion}

Despite these limitations, various strengths and clinical implications of the study should be noted. In general, the sample sizes are not insignificant, providing statistically sound results and confidence in the measure. Additionally, the ability of this measure to glean the importance of the interpersonal context of healing after gender-based trauma can have clinical implications for those seeking help or treatment after experiencing GBV. Importantly, these results reveal that this measure can be used cross-sectionally to understand one's healing progress to date and longitudinally (using just the current feelings portion of the scale) to evaluate recovery-oriented interventions better and understand how healing changes over time. By having a measure that measures survivor-relevant healing benchmarks, we can better understand if interventions are helping survivors reach these more growth-oriented milestones instead of reducing 
symptom burden alone. This instrument also gives us critical healing domains that future interventions can target to meet survivor's holistic needs. By creating a measure grounded in survivor perspectives, however, this instrument is the first of its kind to amplify the healing experiences of those who experience GBV to advance quantitative measurement of this concept. Future studies should build from this research by exploring the GBV-Heal in additional contexts, for example, the various global communities where social attitudes may differ, and concerning specific segments of the population - particularly those at highest risk, such as transgender women (Lanham et al., 2019). This research will improve quantitative research for ever-widening populations, ensuring that our outcome measures are survivor-centered and relevant to their healing goals and desires.

Open Access This article is licensed under a Creative Commons Attribution 4.0 International License, which permits use, sharing, adaptation, distribution and reproduction in any medium or format, as long as you give appropriate credit to the original author(s) and the source, provide a link to the Creative Commons licence, and indicate if changes were made. The images or other third party material in this article are included in the article's Creative Commons licence, unless indicated otherwise in a credit line to the material. If material is not included in the article's Creative Commons licence and your intended use is not permitted by statutory regulation or exceeds the permitted use, you will need to obtain permission directly from the copyright holder. To view a copy of this licence, visit http://creativecommons. org/licenses/by/4.0/.

\section{References}

Aghtaie, N., Larkins, C., Barter, C., Stanley, N., Wood, M., \& Overlien, C. (2018). Interpersonal violence and abuse in young people's relationships in five European countries: Online and offline normalisation of heteronormativity. Journal of Gender-Based Violence, 2(2), 293-310. https://doi.org/10.1332/239868018X15263 879270302

Ahmad, F., Rai, N., Petrovic, B., Erickson, P. E., \& Stewart, D. E. (2013). Resilience and resources among South Asian immigrant women as survivors of partner violence. Journal of Immigrant and Minority Health, 15(6), 1057-1064. https://doi.org/10.1007/ s10903-013-9836-2

Blevins, C. A., Weathers, F. W., Davis, M. T., Witte, T. K., \& Domino, J. L. (2015). The posttraumatic stress disorder checklist for DSM-5 (PCL-5): Development and initial psychometric evaluation. Journal of Traumatic Stress, 28(6), 489-498.

Bovin, M. J., Marx, B. P., Weathers, F. W., Gallagher, M. W., Rodriguez, P., Schnurr, P. P., \& Keane, T. M. (2016). Psychometric properties of the PTSD checklist for diagnostic and statistical manual of mental disorders-fifth edition (PCL-5) in veterans. Psychological assessment, 28(11), 1379.

Browne, M. W., \& Cudeck, R. (1992). Alternative ways of assessing model fit. Sociological Methods \& Research, 21(2), 230-258.

Cerny, B. A., \& Kaiser, H. F. (1977). A study of a measure of sampling adequacy for factor-analytic correlation matrices. Multivariate Behavioral Research, 12(1), 43-47.
Connor, K. M., \& Davidson, J. R. (2003). Development of a new resilience scale: The Connor-Davidson resilience scale (CD-RISC). Depression and Anxiety, 18(2), 76-82.

Crann, S. E., \& Barata, P. C. (2016). The experience of resilience for adult female survivors of intimate partner violence: A phenomenological inquiry. Violence against Women, 22(7), 853-875. https://doi.org/10.1177/1077801215612598

Draucker, C. B., Martsolf, D. S., Ross, R., Cook, C. B., Stidham, A. W., $\&$ Mweemba, P. (2009). The essence of healing from sexual violence: A qualitative metasynthesis. Research in Nursing \& Health, 32, 366-378. https://doi.org/10.1002/nur.20333

Drennan, J. (2003). Cognitive interviewing: Verbal data in the design and pretesting of questionnaires. Journal of Advanced Nursing, 42(1), 57-63.

Duma, S. E., Mekwa, J. N., \& Denny, L. D. (2007). Women's journey of recovery from sexual assault trauma: A grounded theory-Part 1[combined with Part 2]. Curationis, 30(4), 4-11. https://doi.org/ 10.4102/curationis.v30i4.1111.

Flasch, P. (2020). A narrative review of the literature on recovery from intimate partner violence: Developmental processes and facilitating elements. Partner Abuse, 11(1), 39-56. https://doi.org/10. 1891/1946-6560.11.1.39

Flasch, P., Murray, C. E., \& Crowe, A. (2017). Overcoming abuse: A phenomenological investigation of the journey to recovery from past intimate partner violence. Journal of interpersonal violence, 32(22), 3373-3401.

Freyd, J. J., Klest, B., \& Allard, C. B. (2005). Betrayal trauma: Relationship to physical health, psychological distress, and a written disclosure intervention. Journal of Trauma \& Dissociation, 6(3), 83-104.

Fugate, M., Landis, L., Riordan, K., Naureckas, S., \& Engel, B. (2005). Barriers to domestic violence help seeking: Implications for intervention. Violence against Women, 11, 290-310. https:// doi.org/10.1177/1077801204271959

Gallagher, M. W., Lopez, S. J., \& Preacher, K. J. (2009). The hierarchical structure of well-being. Journal of Personality, 77(4), 1025-1050.

Giavarina, D. (2015). Understanding Bland Altman analysis. Biochemia Medica, 25(2), 141-151. https://doi.org/10.11613/BM. 2015.015

Girden, E. R., \& Kabacoff, R. (Eds.). (2010). Evaluating research articles from start to finish. Sage.

Glumbıkova, K., \& Gojova, A. (2019). Transformation of the identity of homeless women with an experience of domestic violence: Changing from a victim to a survivor: An example from shelters for mothers in the Czech Republic. Journal of Social Work Practice, 34(2), 151-162. https://doi.org/10.1080/02650533. 2019.1567479

Gómez, J. M., Lewis, J. K., Noll, L. K., Smidt, A. M., \& Birrell, P. J. (2016). Shifting the focus: Nonpathologizing approaches to healing from betrayal trauma through an emphasis on relational care. Journal of Trauma \& Dissociation, 17(2), 165-185.

Grubaugh, A. L., \& Resick, P. A. (2007). Posttraumatic growth in treatment-seeking female assault victims. Psychiatric Quarterly, 78(2), 145-155.

Hair, J. F., Jr., Hult, G. T. M., Ringle, C., \& Sarstedt, M. (2016). A primer on partial least squares structural equation modeling (PLS-SEM). Sage publications.

Heise, L., Ellsberg, M., \& Gottmoeller, M. (2002). A global overview of gender-based violence. International Journal of Gynecology \& Obstetrics, 78, S5-S14.

Heywood, I., Sammut, D., \& Bradbury-Jones, C. (2019). A qualitative exploration of 'thrivership' among women who have experienced domestic violence and abuse: Development of a new model. BMC women's health, 19(1), 1-15. 
Hooper, D., Coughlan, J., \& Mullen, M. (2008). Structural equation modelling: Guidelines for determining model fit. Electronic Journal of Business Research Methods, 6(1), 53-60.

Kaufman, J. S., Allbaugh, L. J., \& Wright, M. O. (2018). Relational wellbeing following traumatic interpersonal events and challenges to core beliefs. Psychological Trauma: Theory, Research, Practice, and Policy, 10(1), 103-111. https://doi.org/10.1037/ tra0000253.

Keyes, C. L. (2002). The mental health continuum: From languishing to flourishing in life. Journal of Health and Social Behavior, 43(2), 207-222. https://doi.org/10.2307/3090197.

Kleim, B., \& Ehlers, A. (2009). Evidence for a curvilinear relationship between posttraumatic growth and posttrauma depression and PTSD in assault survivors. Journal of Traumatic Stress: Official Publication of The International Society for Traumatic Stress Studies, 22(1), 45-52.

Kroenke, K., Spitzer, R. L., Williams, J. B., Monahan, P. O., \& Löwe, B. (2007). Anxiety disorders in primary care: Prevalence, impairment, comorbidity, and detection. Annals of Internal Medicine, 146(5), 317-325.

Kroenke, K., Strine, T. W., Spitzer, R. L., Williams, J. B., Berry, J. T., \& Mokdad, A. H. (2009). The PHQ-8 as a measure of current depression in the general population. Journal of Affective Disorders, 114(1-3), 163-173.

Lamers, S. M., Westerhof, G. J., Bohlmeijer, E. T., ten Klooster, P. M., \& Keyes, C. L. (2011). Evaluating the psychometric properties of the mental health continuum-short form (MHC-SF). Journal of Clinical Psychology, 67(1), 99-110.

Lanham, M., Ridgeway, K., Dayton, R., Castillo, B. M., Brennan, C., Davis, D. A., et al. (2019). "We're going to leave you for last, because of how you are": Transgender Women's Experiences of Gender-Based Violence in Healthcare, Education, and Police Encounters in Latin America and the Caribbean. Violence and Gender, 6(1), 37-46. https://doi.org/10.1089/vio.2018.0015.

Lewis, S. D., Henriksen, R. C., \& Watts, R. E. (2015). Intimate partner violence: The recovery experience. Women \& Therapy, 38(3-4), 377-394. https://doi.org/10.1080/02703149.2015.1059223.

Martin, C. G., Cromer, L. D., DePrince, A. P., \& Freyd, J. J. (2013). The role of cumulative trauma, betrayal, and appraisals in understanding trauma symptomatology. Psychological Trauma: Theory, Research, Practice, and Policy, 5(2), 110.

Matheson, F. I., Daoud, N., Hamilton-Wright, S., Borenstein, H., Pedersen, C., \& O' Campo, P. . (2015). Where did she go? The transformation of self-esteem, self-identity, and mental wellbeing among women who have experienced intimate partner violence. Women's Health Issues, 25(5), 561-569. https://doi.org/10.1016/j. whi.2015.04.006

Morrison, K. E., Luchok, K. J., Richter, D. L., \& Parra-Medina, D. (2006). Factors infuencing help-seeking from informal networks among African American victims of intimate partner violence. Journal of Interpersonal Violence, 21(11), 1493-1511. https:// doi.org/10.1177/0886260506293484

Nordin, A., Alt Murphy, M., \& Danielsson, A. (2014). Intra-rater and inter-rater reliability at the item level of the Action Research Arm Test for patients with stroke. Journal of Rehabilitation Medicine, 46(8), 738-745. https://doi.org/10.2340/16501977-1831

Oke, M. (2008). Remaking self after domestic violence: Mongolian and Australian women's narratives of recovery. Australian and New Zealand Journal of Family Therapy, 29(3), 148-155. https://doi. org/10.1375/anft.29.3.148

Park, C. L., Cohen, L. H., \& Murch, R. L. (1996). Assessment and prediction of stress-related growth. Journal of personality, 64(1), 71-105.

Ranjbar, V., \& Speer, S. (2013). Revictimization and recovery from sexual assault: Implications for health professionals. Violence and Victims, 28(2), 274-287. https://doi.org/10.1891/0886-6708. 11-00144

R Core Team. (2020). R: A Language and Environment for Statistical Computing. Vienna, Austria. Retrieved from https://www.Rproject.org/

Rodelli, M., Koutra, K., Thorvaldsdottir, K. B., Bilgin, H., Ratsika, N., Testoni, I., \& Saint Arnault, D. M. (2021). Conceptual development and content validation of a multicultural instrument to assess the normalization of gender-based violence against women. Sexuality \& Culture, 1-22.

Saint Arnault, D. M. (2017). The use of the clinical ethnographic narrative interview to understand and support help seeking after gender-based violence. TPM. Testing, Psychometrics, Methodology in Applied Psychology, 24(3), 423.

Schaefer, L. M., Howell, K. H., Schwartz, L. E., Bottomley, J. S., \& Crossnine, C. B. (2018). A concurrent examination of protective factors associated with resilience and posttraumatic growth following childhood victimization. Child Abuse \& Neglect, 85, $17-27$.

Shakespeare-Finch, J., \& Armstrong, D. (2010). Trauma type and posttrauma outcomes: Differences between survivors of motor vehicle accidents, sexual assault, and bereavement. Journal of Loss and Trauma, 15(2), 69-82.

Sharma, S. (1996). Applied multivariate techniques. John Wiley and Sons Inc.

Shrout, P. E., \& Fleiss, J. L. (1979). Intraclass correlations: Uses in assessing rater reliability. Psychological Bulletin, 86(2), 420.

Šimkovic, M., \& Träuble, B. (2019). Robustness of statistical methods when measure is affected by ceiling and/or floor effect. PLOS ONE, 14(8), e0220889. https://doi.org/10.1371/journal.pone. 0220889

Sinko, L., \& Saint Arnault, D. (2020a). Finding the strength to heal: Understanding recovery after gender-based violence. Violence against women, 26(12-13), 1616-1635.

Sinko, L., Munro-Kramer, M., Conley, T., Burns, C. J., \& Arnault, D. M. S. (2020b). Healing is not linear: Using photography to describe the day-to-day healing journeys of undergraduate women survivors of sexual violence. Journal of community Psychology, $48(3), 658-674$

Sinko, L., James, R., \& Hughesdon, K. (2021a). Healing after genderbased violence: a qualitative metasynthesis using meta-ethnography. Trauma, Violence, \& Abuse, 1524838021991305.

Sinko, L., Munro-Kramer, M., Conley, T., \& Saint Arnault, D. (2021b). Internalized messages: The role of sexual violence normalization on meaning-making after campus sexual violence. Journal of Aggression, Maltreatment \& Trauma, 30(5), 565-585.

Smith, M. E. (2003). Recovery from intimate partner violence: A difficult journey. Issues in Mental Health Nursing, 24(5), 543-573.

Smith, B. W., Dalen, J., Wiggins, K., Tooley, E., Christopher, P., \& Bernard, J. (2008). The brief resilience scale: assessing the ability to bounce back. International journal of behavioral medicine, 15(3), 194-200.

Souza, A. C. D., Alexandre, N. M. C., \& Guirardello, E. D. B. (2017). Psychometric properties in instruments evaluation of reliability and validity. Epidemiologia e Serviços De Saúde, 26, 649-659. https://doi.org/10.5123/S1679-49742017000300022

Spitzer, R. L., Kroenke, K., Williams, J. B., \& Löwe, B. (2006). A brief measure for assessing generalized anxiety disorder: The GAD-7. Archives of Internal Medicine, 166(10), 1092-1097.

Substance Abuse and Mental Health Services Administration. (2014). SAMHSA's Concept of Trauma and Guidance for a TraumaInformed Approach. Rockville, MD: HHS Publication No. (SMA) $14-4884$.

Taylor, R. (1990). Interpretation of the Correlation Coefficient: A Basic Review. Journal of Diagnostic Medical Sonography, 6(1), 35-39. https://doi.org/10.1177/875647939000600106 
Taylor, J. Y. (2004). Moving from surviving to thriving: African American women recovering from intimate male partner abuse. Research and Theory for Nursing Practice, 18(1), 35-50.

Tavakol, M., \& Dennick, R. (2011). Making sense of Cronbach's alpha. International Journal of Medical Education, 2, 53-55. https://doi. org/10.5116/ijme.4dfb.8dfd

T , B. G., \& Fidell, L. S. (2013). Using multivariate statistics: International edition. Pearson 2012.

Tedeschi, R. G., \& Calhoun, L. G. (1996). The Posttraumatic Growth Inventory: Measuring the positive legacy of trauma. Journal of Traumatic Stress, 9(3), 455-471.

Ungar, M. (2012). Social ecologies and their contribution to resilience. In The social ecology of resilience (pp. 13-31). Springer, New York, NY.

Van der Kolk, B. A., McFarlane, A. C., \& van der Hart, O. (1996). A general approach to treatment of posttraumatic stress disorder. In B. A. van der Kolk, A. C. McFarlane, \& L. Weisaeth (Eds.), Traumatic stress: The effects of overwhelming experience on mind, body, and society (pp. 417-440). The Guilford Press.

What is gender-based violence? European Commission. (2021, February 5). https://ec.europa.eu/info/policies/justice-and-funda mental-rights/gender-equality/gender-based-violence/what-gender-based-violence_en

Weathers, F. W., Litz, B. T., Keane, T. M., Palmieri, P. A., Marx, B. P., \& Schnurr, P. P. (2013). The PTSD checklist for DSM-5 (PCL5). Scale available from the National Center for PTSD at www. PTSD. Va. gov, 10

Weir, J. P. (2005). Quantifying test-retest reliability using the intraclass correlation coefficient and the SEM. Journal of Strength and Conditioning Research, 19(1), 231-240. https://doi.org/10. $1519 / 15184.1$

Weissman, M. M., \& Bothwell, S. (1976). Assessment of social adjustment by patient self-report. Archives of general psychiatry, 33(9), 1111-1115.

Westerhof, G. J., \& Keyes, C. L. (2010). Mental illness and mental health: The two continua model across the lifespan. Journal of Adult Development, 17(2), 110-119.

World Health Organization. (2013). Global and regional estimates of violence against women: prevalence and health effects of intimate partner violence and non-partner sexual violence. World Health Organization.

Publisher's Note Springer Nature remains neutral with regard to jurisdictional claims in published maps and institutional affiliations. 